$\overline{\text { Case Report }}$

\title{
Hurricane Mitch and Honduras: An illustration of population vulnerability
}

\author{
William C. Smith \\ The Pennsylvania State University, Education Policy Studies, Pennsylvania, USA
}

\section{Abstract}

In 1998, Hurricane Mitch, the fourth strongest Atlantic Ocean hurricane in recorded history, destroyed much of Honduras. Hardest hit were more vulnerable populations of the rural hillside and the urban shanty towns. In the 20 years prior to Hurricane Mitch, a series of neoliberal policies shifted the tax burden to the poor and focused resources on export crops, forcing subsistence farmers to the less arable hillside and leading to deforestation. These moves left the already marginalized in a precarious position when Hurricane Mitch struck as topsoil was washed away and mudslides destroyed hillside farms. Additionally, gendered patterns of privilege were obvious. Men were encouraged to migrate to work leaving women to restore the farm, care for the children, and tend to the elderly. As disaster management is centered on preparation multiple lessons can be learned. First, in preparation multiway information systems need to include actors from the local level and embrace those marginalized by society. Second, women need to be seen as assets not victims and their well-being need to be taken into consideration outside of the family construct. And third, reconstruction effort need to be about building better not faster.

Key words: Disaster management, honduras, hurricanes, vulnerable populations

\section{Introduction}

Natural events such as earthquakes, hurricanes, and tornados do not automatically qualify as natural disasters. Often similar events impact different areas of the world in drastically different ways. The distinguishing factor behind this disparity can be best understood if we expand natural event from a singular, temporal recognition to a process based on a series of decisions that cumulatively impact the outcome. ${ }^{[1]}$ This collection of decisions disproportionately prepares groups, mitigating the effects for some, while enhancing the devastation for others. The latter group are said to be more vulnerable to the event and are therefore more likely to feel the impact of the event as a disaster. Human vulnerability is defined in this framework as "those

\section{Address for correspondence:}

Mr. William C. Smith,

Education Policy Studies, The Pennsylvania State University, 300

Rackley Building, University Park, Pennsylvania - 16823, USA.

E-mail:wcs152@psu.edu

\begin{tabular}{|l|l|}
\hline \multicolumn{2}{|c|}{ Access this article online } \\
\hline Quick Response Code: & Website: \\
\hline & www.ijhsdm.org \\
\hline
\end{tabular}

circumstances that place people at risk while reducing their means of response or denying them protection."[2]

When a natural event occurs in a region that has a high general vulnerability we see the most destructive natural disasters. The 1998 impact of Hurricane Mitch is one such example. Ravaging the vulnerable populations of Central America, it is well-documented as one of the most distressing hurricanes of the $20^{\text {th }}$ century in the Atlantic Ocean. This article is focused on Honduras, the country hardest hit by Mitch. It will start by describing the hurricane itself, followed by a breakdown of the aftermath. Then, the investigation focuses on the most vulnerable populations in Honduras, including rural farmers, the urban poor, and women. The conclusion includes a reflection on the recovery process and the impact it has had on gender relations in the country.

\section{Case Report}

The hurricane

The country of Honduras, nestled on the isthmus of Central America, is no stranger to disaster. Recurrent flooding during the rainy season from May to December often destroys homes, damages agriculture, and contributes to the spread of diseases like cholera. Hurricanes, as well, tend to be common, occurring approximately once every 10 years. ${ }^{[3]}$ The past, however, has done little to shape Honduran policies and preparedness, leaving the 
country extremely vulnerable to Hurricane Mitch; the fourth strongest Atlantic hurricane on record. ${ }^{[4]}$ Mitch lasted longer (15 days) with higher sustained wind gusts $(298 \mathrm{~km} / \mathrm{h})$ and dumped more rain on Honduras and Nicaragua than any other hurricane in recorded history. ${ }^{[5]}$

Mitch became a hurricane at 6 am on October $24^{\text {th }}, 1998$. Its initial location was 255 nautical miles southwest of Jamaica and from there it proceeded west towards the coast of Panama and then north headed for Honduras. The 124 mile wide monster transformed into a category five hurricane on October $26^{\text {th }}$ with $177 \mathrm{mph}$ winds. It spent $33 \mathrm{~h}$ as a category five drenching the coastline of Honduras and Nicaragua. On October $29^{\text {th }}$ it hit mainland Honduras as a category four and within $12 \mathrm{~h}$ was downgraded to a tropical storm. The majority of the destruction was the result of the slow speed of the storm. Traveling less than four knots for the week, Mitch saturated the ground of Honduras causing massive flooding and mudslides. One of the few records that survived the storm indicated 25 inches of rain in $36 \mathrm{~h}$ in southern Honduras, including 10 inches in a $6 \mathrm{~h}$ period. ${ }^{[3,4]}$ Overall, roughly one out of every four people in the country was affected by Hurricane Mitch.

\section{The aftermath}

The 5 days of persistent rain resulted in 25-30 times the amount of rain expected during October, altering and swelling rivers, creating massive floods, and destructive mudflows. At the end, the government reported an official casualty count of 5,657; with 8,058 missing; and another 12,275 injured [Table 1]. ${ }^{[8]}$ In addition over a quarter of a million people were left homeless.

The overall material losses due to Hurricane Mitch reached $\$ 3.8$ billion. The disaster halted economic growth for 1998 (expected to be at $5 \%$ ) and put Honduras into the red in $1999(-2 \%$ change in gross domestic product (GDP)) as they spent $100 \%$ of their international aid on recovery. Mudslides and floods washed away roads leaving many individuals stranded in the country side. Overall, up to $70 \%$ of the national highway system needed to be rebuilt and 92 bridges were damaged or destroyed. The overall estimate of $\$ 579$ million of damage to transportation and communication networks do not take into account the overall economic effect in the region as $90 \%$ of all interstate commerce in Central America flows through this infrastructure. ${ }^{[2,4,6]}$

Eight hundred million dollars were lost in agriculture as destroyed crops led to a $7 \%$ drop in production for $1998 .{ }^{[3]}$ Both domestic and cash crops were heavily impacted by the storm, leaving people unemployed and hungry. Amongst the largest subsistence crop losses included a $58 \%$ reduction in corn production and 24\% reduction in sorghum. Export crop losses included $85 \%$ of all bananas and $60 \%$ of sugar cane. In all more than $29 \%$ of Honduras' arable land was affected by Hurricane Mitch. In addition to loosing farmland, land for livestock grazing, including the livestock itself, was destroyed. Milk and meat production decreased as over 50,000 bovine were killed. Chicken coops crumbled and $60 \%$ of all fowl in the country were killed. ${ }^{[11]}$

Health and education systems were also hit hard by Hurricane Mitch. At a cost of $\$ 33$ million almost one in every four classrooms in Honduras were destroyed; a total of 4,835 out of 20,942 public school classrooms. Of the classrooms that did survive teachers were hard to find; most were trying to restart their life with their family. The healthcare system, which was strengthening prior to Mitch, was overwhelmed. Suffering structural damage, the system was unable to deal with the thousands injured. ${ }^{[6]}$

A total of 123 out of the country's 1,091 medical installations were damaged. Functioning was further impaired by a diminished water source, as landslides and floods made drinking water unsafe and the disposal of waste hazardous. Eighty percent of the country's aqueducts had been affected, cutting off water to 2.9 million people. Twenty-three of the country's 30 hospitals had spoiled water supplies. The lack of clean water was coupled with destroyed sanitation systems leaving many in the marginal urban and poor rural areas covered in sewage, chemical pesticides that had washed away, and decomposing human and animal carcasses. ${ }^{[3]}$ Hurricane Mitch left in its wake an atmosphere perfect for the transfer of communicable diseases. Honduras has a history of infectious diseases which represent six of the top 10 causes of death in the country. One result of the storm was an increase in dengue fever which has been endemic in the country since 1998, when 28,064 cases and 77 deaths were reported. ${ }^{[7]}$ The stagnant, contaminated water produced conditions in which flies could thrive further complicating containment efforts. A small increase in the disease immediately following the hurricane was followed by a larger surge in January 1999. The healthcare system, ill-equipped to respond, was unable to contain the outbreak as only $30 \%$ of surveillance locations were fully functioning. ${ }^{[8]}$

\section{Discussion}

Vulnerable populations

A collection of political and economic decisions during the 20 years leading up to Hurricane Mitch left Honduras vulnerable as a country with particular populations, often left out of the decision-making, on the front line to feel the full force of the disaster. Honduras is a poor country with the forth lowest GDP/capita in Latin America (behind

\begin{tabular}{lccccccc}
\hline \multicolumn{2}{l}{ Table 1: The effects of hurricane mitch } & & & & \\
\hline & Deaths & Missing & Injured & In shelters & Total affected & Directly affected (\%) & Economic losses \\
\hline Nicaragua & 3,045 & 970 & 287 & 65,271 & 867,752 & 19.5 & $\$ 987$ million \\
Honduras & 5,657 & 8,058 & 12,275 & 285,000 & 1.5 million & 24.2 & $\$ 3.79$ billion \\
\hline
\end{tabular}


Bolivia, Haiti, and Nicaragua). Over $70 \%$ of the population lives below the poverty line and one out of two people live in extreme poverty. The bottom $40 \%$ of the country has $7.3 \%$ of the nation's wealth while the top $10 \%$ control $50 \%$ of the wealth. These factors in addition to a $27 \%$ illiteracy rate are a large reason why Honduras was last in the Human Development Index for Latin American countries when Hurricane Mitch hit. ${ }^{[3]}$

In the 1980s Honduras was targeted for development projects by institutions such as the International Monetary Fund (IMF), World Bank, and United States Agency for International Development (USAID). Development programs included contingencies that promoted export crops. As large private farmers moved in to grow bananas, coffee, and melon; small subsistence farmers were forced to the mountain side. This shift in production was accompanied by outstanding debt and within a few years repayment of external debt took priority over conservation of natural resources. Since the 1980s debt crisis, the economy in Honduras has stagnated; the increase in GDP $(2.3 \%)$ is unable to keep pace with the population growth $(2.9 \%)$. The neoliberal policies inculcated in Honduras resulted in $60 \%$ of all companies being controlled by US firms in 1989. The path being taken by the country's economy was encouraged by president Rafael Callejas who in 1989 liberalized trade and devalued the country's currency. As money flowed in from international sources, the wealthy siphoned their share of the top, and the corruption compounded the prevalent economic inequality. ${ }^{[3]}$ Neoliberal practices that widen the gap between the wealthy and the poor continued up to and through Hurricane Mitch. The Honduras government, supported by the Inter-American Development Bank raised sales tax from $7 \%$ to $12 \%$ in 1998 , while reducing the income tax paid by the wealthy by $10 \%$ from 35 to $25 \%$-a fiscal policy that shifted the tax burden to the middle and lower classes. ${ }^{[6]}$

The majority of the poor in Honduras are found in either of the marginal areas surrounding urban centers or on the rural hillside. Following the movement to export crops, small farmers were forced up on the hillsides resulting in massive deforestation-as of 1993 at a rate of 10,000 hectares per year. The process of deforestation started in the last half of the $20^{\text {th }}$ century but intensified in the last 2 decades as large population growth led to environmental degradation. Overgrowing and the overuse of pesticides, in addition to the removal of trees, led to the loss of 3 million tons of topsoil during this time span. Without anything to hold the topsoil in place the torrential rains of Hurricane Mitch led to widespread mudslides. ${ }^{[2]}$ There was a significant portion of farmers that choose not to move to the hillside and instead moved to the city. This urbanization movement resulted in shanty towns, outlining the urban core, that were inflicted with overcrowding, violence, poor sanitation, and poor housing.

Within the rural and urban poor, women are especially vulnerable. The inequality in the economic sector can be seen through their head of household rate (20\%) and share of total earned income (24.8\%). Females in Honduras are generally seen in the stereotypical sectors of domestic work, child rearing, and small subsistence farming. Pregnancy itself, in a country that is still strengthening its health infrastructure, is a risk. The overall maternal mortality rate is 220 per 100,000 live births, a number that jumps to 391 for girls aged 12-14 years. This statistic is exasperated by a total fertility rate of 5.3 children per women with a much more pronounced 8.7 children per women in rural areas. ${ }^{[3]}$ Differences in socioeconomic status coupled with lack of power in domestic relationships, lack of access to resources such as land, underrepresentation in the political process, and inability to physically escape from a storm by climbing on top of a structure or swimming greatly increased the likelihood that women would feel the brunt of the disaster. ${ }^{[9]}$

Two specific examples illustrating female participation before Hurricane Mitch involve gender participation in emergency planning. In a country with a history of natural disasters, emergency committees often failed to consult with local people. When consultations did take place; they were almost always exclusively male, perpetuating the belief that women are merely victims not assets. Secondly, emergency committees assumed a two parent household, assigning responsibilities to each party. As a result female headed households were forced to choose between their children and their assets. Most choose their children and lost the means to support their livelihood.

Recovery: Reflecting on vulnerable populations Hurricane Mitch brought a mix of both positive and negative effects to gender relations in Honduras. In the recovery phase, women were seen with a "can-do spirit" and surprised emergency workers by their willingness to take on and ability to complete tasks that were deemed outside of their traditional roles. Women hauled cement, dug out wells, and fixed damaged fences. There was also a sharp increase in female headed households, a year after the disaster the amount of female headed households more than doubled from $20 \%$ prior to Mitch to over $50 \%$. For females this was both a rise in autonomy as well as a burden as men often left their families, migrating to find work.

As a more vulnerable population, women faced many negative outcomes immediately following the storm. A gender imbalance was seen in the participation of recovery groups. The Food for Work program provided training, food, and work only for men and some faith based organizations prohibited women from construction work because it was not their "natural role". Women, however, seemed to be busier in their daily life than men as the government encouraged male migration to seek employment, leaving women to rebuild their life, support their children, and shoulder a greater burden caring for the elderly. Furthermore, the areas most affected by flooding tended to be small subsistence farms. These farms were often run by women to feed their family, while men worked on 
larger cash crops. After the destruction, short-term income opportunities were disproportionately offered to males. ${ }^{[5]}$

Honduras also saw an increase in sexual and domestic violence. In 1998 prior to Hurricane Mitch; 46,200 cases of sexual or domestic violence were reported, in 2000 the number of cases jumped to 54,270 . In a 2000 survey, eight out of 10 women claimed to have been the victim of domestic violence. ${ }^{[10]}$

Instability following the disaster led to more females invading "male space" such as working in factories. Males migrated more for work bringing more men and women in contact with each other in stressful situations. These trends, combined with the subservient demeanor expected of women, led to an increase in human immunodeficiency virus (HIV). The male-female ratio for HIV incidence was $2: 1$ in the late 1980s; by 2000 it had shifted to $1: 1 .^{[11]}$

Several changes that occurred after Hurricane Mitch were seen as steps forward for the country as well as those most vulnerable. The Inter-American Development Bank provided loans that took into account needs created by the disaster. ${ }^{[11]}$ Healthcare in Honduras was reformed as the Ministry for Public Health focused its 1999-2001 policy on the principles of solidarity, equity, participation, quality, and transparency. ${ }^{[11]}$

Working particularly with the rural and marginalized urban population were groups such as the Canadian Red Cross and the American Friends Service Committee (AFSC). The Canadian Red Cross worked, in concert with the International Organization for Migration (IOM), to build 150 homes in Honduras' hard hit rural area. Previous dwellings in high risk areas were demolished and new buildings included running water and sanitation. ${ }^{[12]}$ The AFSC had a comprehensive recovery plan that included relief, disease prevention and health, infrastructure support and economic reactivation. At a cost of over $\$ 1.75$ million they directly impact over three quarters of a million people. See Table 2 for a breakdown. ${ }^{[13]}$

\section{Suggestions for disaster management}

Future efforts to mitigate the effect of disasters on vulnerable populations cannot wait until the next event. Multiway information exchange systems need to include actors from the local level and embrace those marginalized

\begin{tabular}{lcc}
\hline Table 2: Final figures for AFSC & response & \\
\hline Type of program & $\begin{array}{c}\text { Number of } \\
\text { projects }\end{array}$ & $\begin{array}{c}\text { Directly benefited } \\
\text { (Number of individuals) }\end{array}$ \\
\hline Relief & 22 & 88,404 \\
Disease prevention and health & 16 & 625,246 \\
Infrastructure and relocation & 13 & 7,498 \\
Economic reactivation & 20 & 49,947 \\
Participatory processes & 10 & \\
Total & 81 & 771,095 \\
\hline
\end{tabular}

AFSC: American Friends Service Committee by society. Citizens need to be involved in the preparation of disaster plans as well as other political decisions that lead to increased vulnerability. This work has begun to be actualized in Honduras as the breakdown of some gender norms in the wake of Hurricane Mitch has resulted in more husbands listening and valuing the opinions of their wives.

Secondly, women need to be seen as assets not victims and demographically their well-being need to be taken into consideration outside of the family construct. Most recovery actors, following the disaster, did not differentiate the woman's needs from the family needs, assuming that a) all families have the same gender composition and $b$ ) there is an equal share in the decision making power and resources within the family.

Finally, the reconstruction effort needs to be about building better not building faster. The "tyranny of the urgent" reduces participation by local citizens due to a perceived time constraint. Feeling rushed for time outside agencies are only consulted, if consulted at all, by political elites. In Honduras this has led to an emphasis on infrastructure and a lack of funding for women's priorities such as food security, water, sanitation, and healthcare.

\section{Acknowledgement}

The study was unfunded and the author has no conflict of interests to disclose.

\section{References}

1. Oliver-Smith A. Understanding hurricane Mitch:Complexity, casualty, and the political ecology of disaster. In: Ensor M, editor. The Legacy of Hurricane Mitch. Phoenix: University of Arizona Press; 2009. p. 1-21.

2. Comfort L, Wisner B, Cutter S, Pulwarty R, Hewitt K, Oliver-Smith A, et al. Reframing disaster policy: The global evolution of vulnerable communities. Environ Hazards 1999;1:39-44.

3. Ensor B, Ensor M. Hurricane Mitch: Root causes and responses to the disaster. In Ensor M, editor. The Legacy of Hurricane Mitch. Phoenix: University of Arizona Press; 2009. p. 22-47.

4. Hurricane Mitch Reports. Available from: http://www.huricannemitch. com [Last accessed 2010 Jan 27].

5. Delaney P, Shrader E. Gender and post-disaster reconstruction: The case of Hurricane Mitch in Honduras and Nicaragua. LCSPG/LAC Gender Team-The World Bank; 2000.

6. Central America after Hurricane Mitch: The challenge of turning a disaster into an opportunity. Inter-American Development Bank. Available from: http://www.iabd.org/regions/re2/consultative_group/backgrounder2. html [Last accessed 2010 Jan 27].

7. Honduras: Specific health problems. PAHO. Available from: http://www. paho.org/english/dd/ais/cp_340.html [Last accessed 2010 Jan 27].

8. Shoaf KI, Rottman, SJ. Public health impact of disasters. Aust J Emerg Manage 2000;15:58-63.

9. Ensor M. Gender matters in post-disaster reconstruction. In Ensor M, editor. The Legacy of Hurricane Mitch. Phoenix: University of Arizona Press; 2009. p. $129-56$.

10. Ensor (2009).

11. Honduras: Specific Health Problems.

12. Rebuilding after Hurricane Mitch: Housing reconstruction in Honduras and Nicaragua. International Federation of Red Cross and Red Crescent Societies. Available from: http://www.proventionconsortium.org/ 
themes/default/pdfs/IFRC_Mitch_recovery07.pdf [Last accessed 2010 Jan 27].

13. Hurricane Mitch 5 years later. American Friends Service Committee. Available from: http://www.afsc.org/mexico-summerproject/ht/a/ GetDocumentAction/i/45194 [Last accessed 2010 Jan 27]. :
How to cite this article: Smith WC. Hurricane Mitch and Honduras: An illustration of population vulnerability. Int J Health Syst Disaster Manage 2013;1:54-8.

Source of Support: Nil, Conflict of Interest: None declared. 